\title{
Comparison of Complex Formation Mechanisms in Hydrogen Abstraction Reaction between the Nitro Compound and Ammonia ${ }^{\dagger}$
}

\author{
Dmitry Ovsyannikov * and Vadim Lashchenov \\ Chemistry Department, Lobachevsky State University of Nizhni Novgorod, Nizhni Novgorod 603950, \\ Russia; lashonov.vadim@gmail.com \\ * Correspondence: ovsyannikov@chem.unn.ru \\ + Presented at the 22nd International Electronic Conference on Synthetic Organic Chemistry, 15 November- \\ 15 December 2018; Available Online: https://sciforum.net/conference/ecsoc-22.
}

Published: 14 November 2018

\begin{abstract}
The present work aims to compare two possible pathways of a pre-reaction complex in the reaction of transfer of a hydrogen atom from ammonia to a nitro compound forming. Nitrobenzene, nitromethane, and $\mathrm{HNO}_{2}$ were used as nitro compounds. The proposed paths are: nitro compound intersystem crossing with a subsequent search for a substrate, or the formation of a complex with its subsequent excitation. The calculations were performed using TDPBE0/TDA/aug-cc-pVDZ method in NWChem-6.8 program. For verification purposes, some additional calculations were performed using RASCI/aug-cc-pVDZ method in PSI4 program. The location of the levels and the geometry of the complexes shows that the triplet complex (exciplex) is more stable than the singlet complex. The weak coupling between molecules in the singlet complex indicates that the probability of its excitation is very small. Moreover, there are experimental data, where the quantum yields of such reactions reach 0.3. The presented calculations confirm the mechanism of the nitro compound intersystem crossing with a subsequent search for a substrate.
\end{abstract}

Keywords: photoreduction; amines; nitro compound; excited state; hydrogen abstraction; photochemistry; quantum chemistry

\section{Introduction}

Hydrogen transfer reactions involving excited nitro compounds have been studied for a long time. It is known that in the triplet state, aromatic nitro compounds are able to hydrogen atom abstraction from amines and ketones [1,2]. For example, according to the scheme

$$
{ }^{3}\left(\mathrm{ArNO}_{2}\right)+\left(\mathrm{CH}_{3}\right)_{2} \mathrm{CHOH} \rightarrow \mathrm{ArNO}_{2} \mathrm{H}+\left(\mathrm{CH}_{3}\right)_{2} \dot{\mathrm{COH}},
$$

the triplet nitro compound reacts with alcohol and yields the radical pair. The mechanism of such a reaction is complicated. It may include direct or sensitized photoexcitation. These may be dark radical processes or occur under the action of light. Initial electron transfer with the yield of ion-radicals is possible.

It has been established that in an air-saturated atmosphere the quantum yield of the hydrogen transfer reaction drops sharply [3]. This suggests participation in the reaction of triplet particles.

The current work aims to compare the possibility of forming a pre-reaction complex of different multiplicities. The formation of a strong-bonded complex between reactants is expected. Then, a photoexcitation takes place, followed by an intersystem transition. An alternative mechanism is the initial excitation of the nitro compound with the subsequent formation of a pre-reaction complex.

\section{Methodology}


The formation energy comparison of the pre-reaction complex between nitro compound and substrate was performed. The model systems are:

$$
\begin{gathered}
\left\{\mathrm{HNO}_{2}+\mathrm{NH}_{3}\right\} \\
\left\{\mathrm{CH}_{3} \mathrm{NO}_{2}+\mathrm{NH}_{3}\right\} \\
\left\{\mathrm{PhNO}_{2}+\mathrm{NH}_{3}\right\}
\end{gathered}
$$

All systems are calculated using TDPBE0/aug-cc-pVDZ time-depended hybrid functional. NWChem-6.8 [4] was used for this purpose. Table 1 summarizes the geometry parameters of $\mathrm{CH}_{3} \mathrm{NO}_{2}$ in singlet state for some DFT (Density Functional Theory) functionals. TDPBE0 with aug-cc-pVDZ basis set is acceptable for current molecule.

Table 1. $\mathrm{CH}_{3} \mathrm{NO}_{2}$ in singlet state geometry comparison.

\begin{tabular}{ccccc}
\hline Parameter & $\begin{array}{c}\text { TDPBE0/aug- } \\
\text { cc-pVDZ }\end{array}$ & $\begin{array}{c}\text { M06-2X/aug- } \\
\text { cc-pVTZ }^{1}\end{array}$ & $\begin{array}{c}\text { B3PW91/6- } \\
\text { 31g(2df,p) }^{{ }^{1}}\end{array}$ & Experimental 2 \\
\hline $\mathrm{r}(\mathrm{C}-\mathrm{H})^{*}$ & 1.092 & 1.083 & 1.088 & 1.088 \\
\hline $\mathrm{r}(\mathrm{C}-\mathrm{N})^{*}$ & 1.486 & 1.492 & 1.492 & 1.489 \\
\hline $\mathrm{r}(\mathrm{N}-\mathrm{O})^{*}$ & 1.215 & 1.206 & 1.216 & 1.224 \\
\hline $\mathrm{a}(\mathrm{H}-\mathrm{C}-\mathrm{N})^{* *}$ & 106.5 & 106.7 & 106.8 & 107.2 \\
\hline $\mathrm{a}(\mathrm{O}-\mathrm{N}-\mathrm{O})^{* *}$ & 125.6 & 124.5 & 126.1 & 125.3 \\
\hline
\end{tabular}

* $\mathrm{r}$ - distance between atoms, $\AA$; ${ }^{* *} \mathrm{a}$-valence angle, degrees; $1 \mathrm{https://cccbdb.nist.gov;} 2$ Hellwege K.H., Hellwege A.M. (ed.). Landolt-Bornstein: Group II: Atomic and Molecular Physics Volume 7: Structure Data of Free Polyatomic Molecules. Springer-Verlag. Berlin. 1976.

Some of the calculations were performed using RASCI/aug-cc-pVDZ [5] method (Restricted Active Space Configurational Interactions) in PSI4 [6] program. For (3) complexes on ground tripletstate active space contains: RAS1 -6 orbitals, RAS2 -3 orbitals, RAS3 -3 orbitals, RAS4 -6 orbitals with a total of 18 electrons on 18 orbitals. The arbitrary calculations using RASSCF(4,4,4)/cc-pVDZ for (3) complex were performed. On singlet-state complex the following natural orbital (NO) occupation numbers were received:
A 1.990012
A 1.989464
A 1.979117
A 1.976980
A 1.975171
A 1.892838
A 0.129193
A 0.029386
A 0.018901
A 0.010374
A 0.007504
A 0.001060

Letter A means orbital symmetry. Complexes has $C_{1}$ point group, so all orbitals have the same symmetry. One HONO (Highest Occuped Natural Orbital) and 3 LUNO (Lowest Unoccuped Natural Orbital) are with low contributions and may be neglected in calculations. As expected, a similar singlet-state cannot be described with one-determinant wavefunction. The most important determinants are:

$$
\begin{aligned}
& \text { * } 1 \text {-0.950525 ( 0, 0) 16AX 17AX 18AX 19AX 20AX 21AX } \\
& \text { * } 20.201064(2,2) \text { 16AX 17AX 18AX 19AX 21AX 22AX }
\end{aligned}
$$

This distribution indicates that one-determinant methods are not reliable for current systems. So comparison with multi-determinant methods is required.

PSI4 provides symmetry adapted perturbation theory (SAPT) [7] which may be used to calculate intermolecular coupling energy. The aug-cc-pVDZ basis set with SAPT0 method was used. 


\section{Results and Discussion}

Table 2 summarizes formation energies of (2), (3) and (4) complexes in singlet and triplet states. First of all, $3\left\{\mathrm{RNO}_{2}+\mathrm{NH}_{3}\right\}$ PBE0 energy was obtained using PSI4 program. Formation energy are calculated as difference between absolute energy of complex and sum of separated molecules energies. As we can see, SAPT0 gives formation energy of 1.2-1.8 times higher than TDDFT (TimeDepended Density Functional Theory). SAPT on higher levels of theory can give lower energy. However, SAPT2 and higher are not available for unrestricted wavefunctions in PSI4. For triplet-state complex (3) RASCI gives the formation energy of $7.46 \mathrm{~kJ} \cdot \mathrm{mol}^{-1}$. These energies are very close to each other for singlet-state and triplet-state complexes.

Figure 1 shows the singlet and triplet (2) complex. $\mathrm{HNO}_{2}$ geometry depends on multiplicity. In the singlet state four atoms are lying in one plane. In the triplet state $\mathrm{H}$-atom departs from $\mathrm{N}-\mathrm{O}-\mathrm{O}$ plane.
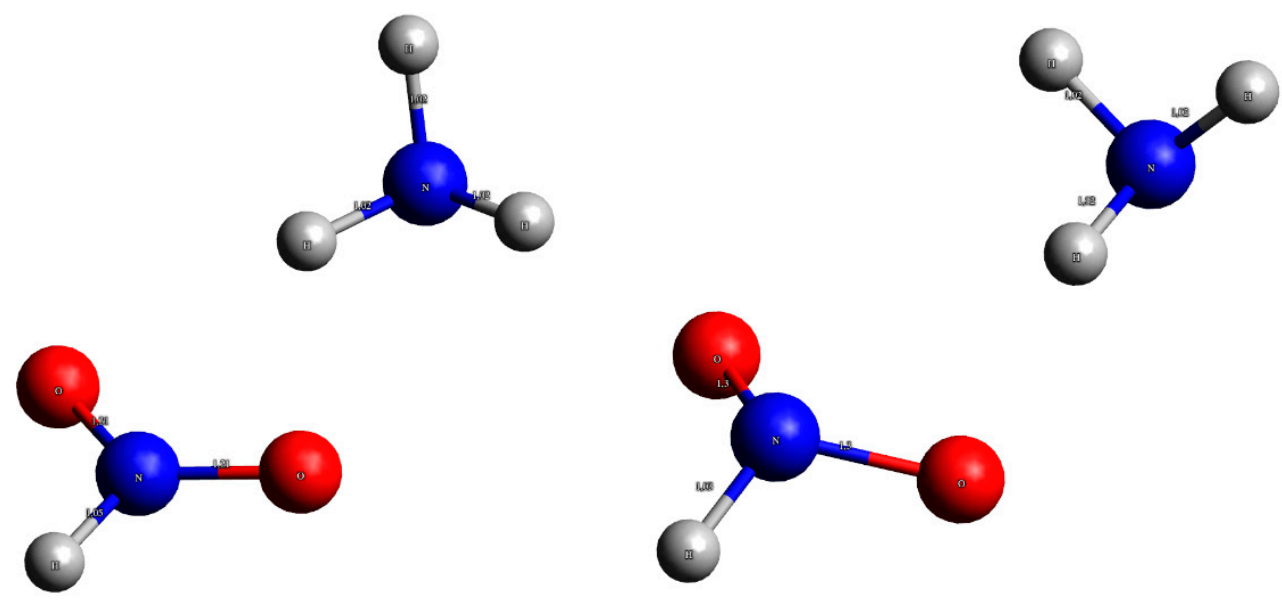

(a)

(b)

Figure 1. $\mathrm{HNO}_{2}+\mathrm{NH}_{3}$ geometry in (a) singlet (b) triplet state.

Table 2. Complex formation energies comparison.

\begin{tabular}{|c|c|c|c|c|}
\hline \multirow{2}{*}{$\begin{array}{c}\mathrm{RNO}_{2} \\
\text { where } \mathrm{R}=\end{array}$} & \multicolumn{2}{|c|}{ Singlet } & \multicolumn{2}{|c|}{ Triplet } \\
\hline & TDPBE0, $\mathrm{kJ} \cdot \mathrm{mol}^{-1}$ & SAPT0, $\mathrm{kJ} \cdot \mathrm{mol}^{-1}$ & TDPBE0, $\mathrm{kJ} \cdot \mathrm{mol}^{-1}$ & SAPT0, $\mathrm{kJ} \cdot \mathrm{mol}^{-1}$ \\
\hline $\mathrm{H}$ & -4.41 & -7.81 & -5.06 & -9.39 \\
\hline $\mathrm{CH}_{3}$ & -7.04 & -9.18 & -6.35 & -10.18 \\
\hline $\mathrm{Ph}$ & -7.97 & -10.18 & -5.21 & -12.70 \\
\hline
\end{tabular}

Note the tendency for energies of TDPBE0 and SAPT0 in Table 2 are different. Formation energy of triplet complexes calculated using SAPT0 decreases continuously, but TDPBE0 violates this dependence for complex (4). In singlet complexes the tendencies are the same: continuously decreasing for complexes (2)-(4).

\section{Conclusions}

Comparing the formation energies of complexes between nitro compounds and ammonia we concluded that there is no significant energetic preference in singlet-state and triplet-state complexes formation. Evidently, weak-coupled, both of them cannot exist for a long time. An immediate exposure to light on the singlet-state complex or the initially excited into triplet manifold nitro compound is needed. Therefore, it may be concluded that initial triplet state complex is the preferable reaction pathway. The next stage of the reaction would be hydrogen atom abstraction from amine molecule to nitro compound, as described in ref [8]. 


\section{References}

1. el Latif, F.M.A.; Barsy, M.A.; Rady, E.A.; Hassan, M.E.; el Maghraby, M.A. Photoinduced reaction of polyfunctional nitroaromatics: photoreduction versus photosubstitution reaction of nitrobenzylidene malonic derivatives with triethylamine. J. Photochem. Photobiol. Chem. 1999, 121, 111-117.

2. Ho, T.-I.; Chow, Y.L. Photochemistry of Nitro and Nitroso Compounds. In PATAI'S Chemistry of Functional Groups; American Cancer Society: Atlanta, GA, USA, 2009.

3. Görner, H.; Döpp, D. Photoreduction induced by electron transfer from di- and trialkylamines to the triplet state of nitronaphthalenes in polar media. J. Chem. Soc. Perkin Trans. 2002, 2, 120-125.

4. Valiev, M. NWChem: A comprehensive and scalable open-source solution for large scale molecular simulations. Comput. Phys. Commun. 2010, 181, 1477-1489.

5. Sherrill, C.D.; Schaefer, H.F. The Configuration Interaction Method: Advances in Highly Correlated Approaches. In Advances in Quantum Chemistry, Löwdin, P.-O., Sabin, J.R., Zerner, M.C., Brändas, E., Eds.; Academic Press: Cambridge, MA, USA, 1999; Volume 34, pp. 143-269.

6. Parrish, R.M. Psi4 1.1: An Open-Source Electronic Structure Program Emphasizing Automation, Advanced Libraries, and Interoperability. J. Chem. Theory Comput. 2017, 13, 3185-3197.

7. Jeziorski, B.; Moszynski, R.; Szalewicz, K. Perturbation Theory Approach to Intermolecular Potential Energy Surfaces of van der Waals Complexes. Chem. Rev. 1994, 94, 1887-1930.

8. Ovsyannikov, D.V.; Zelentsov, S.V. Quantum-Chemical Study of the Oxidative Ability of Nitro Compounds Using Decomposition of Some Simple Amines in the Presence of Triplet Nitromethane as an Example. High Energy Chem. 2018, 52, 217-221.

(C) 2019 by the authors. Licensee MDPI, Basel, Switzerland. This article is an open access article distributed under the terms and conditions of the Creative Commons Attribution (CC BY) license (http://creativecommons.org/licenses/by/4.0/). 